\title{
DIFICULDADES DE APRENDIZAGEM EM MATEMÁTICA: TEMÁTICA AUSENTE NA FORMAÇÃO INICIAL DO PEDAGOGO
}

\section{LEARNING DIFFICULTIES IN MATHEMATICS: INEXISTENT THEME IN THE INITIAL TEACHER FORMATION}

\author{
Sandra Monteiro Gomes ${ }^{1}$ \\ ORCID iD: $\underline{0000-0002-0395-4366}$
}

Rute Cristina Domingos da Palma ${ }^{2}$

ORCID iD: 0000-0001-7650-5556

\begin{abstract}
RESUMO
Com o objetivo de analisar como a temática "dificuldades de aprendizagem em matemática" é abordada durante o processo formativo do futuro professor que atuará nos anos iniciais do Ensino Fundamental, esta pesquisa procura responder ao problema: "Como as dificuldades de aprendizagem em matemática são abordadas nos cursos de Pedagogia de Porto Velho-RO?". A pesquisa fundamenta-se no referencial teórico sobre a formação matemática nos cursos de Pedagogia e as dificuldades de aprendizagem em matemática. Da pesquisa de cunho qualitativo participaram 3 professores que atuam na formação matemática e 39 licenciandos de três Instituições de Ensino Superior que ofertam o curso de Pedagogia. Para a produção dos dados realizaram-se entrevistas com os professores responsáveis pelas disciplinas que tratam da formação matemática e grupos focais com licenciandos do curso de Pedagogia. Os professores e os licenciandos sinalizam que a temática não é discutida no curso, e os últimos, não se sentem preparados para lidar com as dificuldades de aprendizagem em matemática. Há, portanto, a necessidade de repensar a formação inicial de professores, de maneira a promover essa discussão articulando-a com a formação continuada, com vistas à melhoria dos processos de ensino-aprendizagem da matemática.
\end{abstract}

Palavras-chave: Dificuldades de aprendizagem. Formação inicial. Matemática.

\begin{abstract}
With the aim of analyze how the theme Learning difficulties in mathematics had been addressed during the formation process about the future teacher who will act in the early years of elementary school. This research attempts to answer the problem: $\mathrm{How}$ the Learning difficulties in mathematics had been addressed in the pedagogy course in Porto Velho-RO? The research is based in the theoretical reference about the mathematical education in the pedagogy course and the Learning difficulties in mathematics. Participated in this survey, three teachers who act in the mathematics formation and 39 undergraduate students from three different Higher educations institutions who offer the pedagogy course. For the data production was carried out interview with the sponsor teachers for the disciplines who discuss about mathematics formation and focus groups with undergraduate students of pedagogy course. The teachers and the undergraduate students assert that the theme is not discussed in the course, and about the last years, they do not feel able to work with the Learning difficulties in mathematics. There is, therefore, the
\end{abstract}

\footnotetext{
${ }^{1}$ Doutorado em Educação, em Ciências e Matemática pela Universidade Federal do Mato Grosso (UFMT). Professora do curso de Licenciatura em Física no Instituto Federal de Educação, Ciências e Tecnologia de Rondônia (IFRO), Porto Velho, Rondônia, Brasil. Rua Salvador, SN, bairro Embratel, Porto Velho, Rondônia, Brasil, CEP: 76820-730. E-mail: sandra.gomes@ifro.edu.br.

2 Doutorado em Educação pela Universidade Estadual de Campinas (UNICAMP). Docente do Instituto de Educação da UFMT, Cuiabá, Mato Grosso, Brasil. Rua Haiti, n.804, Edifício Belle Vie Residence, apto 1502, T 2, Bairro Jardim das Américas, Cuiabá, Mato Grosso, Brasil, CEP:78060-618. E-mail: rutecristinad@ gmail.com.
} 
need to rethink the initial teacher formation as way that promotes the discussion about the continued formation, for the improvement of processes of the teaching-learning of Maths.

Keywords: Learning difficulties. Initial formation. Mathematics.

\section{INTRODUÇÃO}

O constante diálogo com os professores que atuam nos anos iniciais aproxima-nos das discussões presentes (ou não) na escola acerca do baixo rendimento em matemática, anunciado ora pelas avaliações de larga escala, ora pelo acompanhamento do professor na resolução das atividades pelos alunos. Diante do fracasso escolar de parte dos alunos, um discurso que ecoa na sala de professores e nas reuniões de pais é que os alunos não aprendem matemática ou possuem dificuldades para aprender. Nesse contexto, há relatos de que os professores encontram dificuldades em lidar com as crianças que não seguem o mesmo ritmo dos demais e, ainda, uma tendência a patologizar esse processo e culpar a criança por suas dificuldades. É a partir desse contexto que consideramos importante compreender como os cursos de Pedagogia abordam as dificuldades de aprendizagem em matemática.

São os futuros professores preparados para compreender o que é uma dificuldade de aprendizagem em matemática ou uma dificuldade para resolver determinadas atividades escolares? Os dados das avaliações de larga escala têm sido problematizados? Como lidam com as situações que exigem atenção maior dos professores na condição de estagiários? O processo de ensino pode gerar situações de dificuldades de aprendizagem? Como o curso de Pedagogia tem abordado essa discussão? Esses questionamentos foram desencadeadores da pesquisa que busca respostas à indagação: como as dificuldades de aprendizagem em matemática são abordadas nos cursos de Pedagogia de Porto Velho-RO?

A pesquisa foi desenvolvida em 3, das 4 instituições que ofertam o curso de Pedagogia em Porto Velho-Rondônia. E para compreender o que vivenciam no curso, os 3 professores que ali atuam na formação matemática foram entrevistados e, em cada instituição, grupos focais foram desenvolvidos com os licenciandos que cursavam o último ano do curso, totalizando a participação de 39 futuros professores. A partir do referencial teórico e dos aspectos que emergiram dos dados, uma das categorias de análise, aborda "As vivências de alunos de Pedagogia e professores formadores com relação à temática dificuldade de aprendizagem em matemática". 
O texto apresenta uma discussão inicial sobre as dificuldades de aprendizagem em matemática e a formação do professor, bem como a produção e análise dos dados e as considerações finais.

\section{REFERÊNCIAL TEÓRICO}

\section{DIFICULDADES DE APRENDIZAGEM EM MATEMÁTICA E A FORMAÇÃO DO PROFESSOR}

É oportuno destacar que as dificuldades de aprendizagem em matemática vêm sendo retratadas em diversas pesquisas (COUTO, 2016; FONSECA, 2014; LIMA, 2017; MULLER, 2012; PLAZZA, 2010; RÊGO, 2014; SILVA, 2012; SILVA; DARSIE, 2014; SULEIMAN, 2016; VIANA, 2011), e a discussão emerge nas unidades escolares, sobretudo, quando o resultado das avaliações em larga escala é divulgado.

Diante dos resultados, a muitas crianças são atribuídas dificuldades de aprendizagem. Os relatos médicos, envolvendo crianças "normais" com problemas escolares, surgiram na literatura inglesa no final do século passado com o oftalmologista Hinshelwood, um escocês que, em 1917, diante de um problema detectado, nominou a dificuldade de aprendizagem como “cegueira congênita das palavras". Outro precursor, Samuel Orton, neuropatologista americano, em 1925, passou a empregar o termo "estrefossimbolia" para definir distorções, substituições e omissões observadas na caligrafia (CIASCA, 2003).

As dificuldades de aprendizagem, no entanto, se tornaram lócus de interesse na América do Norte somente no final dos anos de 1960, estabelecendo-se um campo de atuação profissional apoiado pelo legislativo dos Estados Unidos, que então, empreendeu forças para a criação de um Comitê Nacional Conjunto sobre Dificuldade de Aprendizagem, o National Joint Comitee of Learning Disability - NJCLD (SISTO et al., 2004).

O termo "dificuldade de aprendizagem", como conceito, foi criado tão somente em 06 de abril de 1963 (data considerada um marco no processo inicial no campo de estudos das dificuldades de aprendizagem), em uma reunião mobilizada por um grupo de pais, que, preocupados com seus filhos, organizaram uma equipe formada por diversos especialistas. Reuniram-se em Chicago (SÁNCHEZ, 1998), com a presença de Samuel Kirk, apontado como o pai do termo, com o objetivo de explicar e propor soluções para as dificuldades observadas.

Sánchez (1998) relembra que, nos primeiros cinco anos de estudos, o grupo americano, ao utilizar os testes de inteligência, classificou as dificuldades de aprendizagem em cinco categorias distintas: aprendizes lentos; retardados mentais; transtornados emocionais; privados 
culturalmente; e portadores de dificuldades de aprendizagem, denominações, que, com o passar dos anos, foram se reestruturando conforme esses estudos foram avançando.

Desde então, diversas ações culminaram em avanços significativos na forma de compreender tais questões e lidar com elas, como: a) criação de uma confederação que propôs, desde 1981, definições mais unificadas para as dificuldades de aprendizagem; b) criação, nos Estados Unidos, de uma legislação específica sobre o campo, a Lei Pública 94.142, de 1975; c) ampliação dos serviços educativos; e d) trabalho conjunto de pais, professores e especialistas na busca de soluções.

Os movimentos internacionais surgidos nas décadas de 1980 influenciaram políticas públicas e ações diferenciadas para inclusão, motivando estudos em áreas como Pedagogia, Psicologia e Medicina (SILVA; LUZIO; SANTOS, 2012).

Neste estudo, partimos da compreensão de que dificuldades de aprendizagem referemse a uma limitação, as quais envolvem aspectos multifatoriais, mas ligados principalmente a fatores de ordem extrínseca ao indivíduo, enquanto os transtornos de aprendizagem são concebidos a partir de uma perspectiva clínico-médica, ligados a aspectos intrínsecos, e, após diagnosticados, exigem um trabalho conjunto entre os profissionais de saúde e educação.

Acontece que, permeados por uma concepção biologista, ou, ainda, por uma concepção clínica aplicada inadequadamente no espaço escolar, estudantes, principalmente, aqueles que precisam de mais atenção e empenho da escola, não estão tendo o devido acompanhamento. Desse modo, temos presenciado crianças saudáveis sendo excluídas ou, ainda, medicadas, simplesmente por encontrar-se em situação de dificuldade na escola ou por "não acompanharem a sua turma" a contento.

Mello (2007), levanta a questão de que as metodologias de ensino estão muito pautadas no produto, e não no processo de aprendizagem; destaca que, geralmente, elas são realizadas com a classe toda da mesma forma e, ao mesmo tempo, com conteúdos fixos e prazos determinados para serem "ensinados" e "aprendidos", o que muitas vezes impossibilita os alunos de apropriar-se do sentido desses conteúdos para a sua vida. Desse modo, caracteriza-se não como "dificuldades de aprendizagem", mas como "dificuldades de ensino", provenientes de vários problemas atrelados à organização escolar e curricular, à formação do professor, às condições de trabalho, entre outras, já debatidas exaustivamente na literatura da área de Educação.

Por outro lado, a escola, ao invés de criar estratégias para minimizar esses preconceitos estabelecidos, muitas vezes, os reforça, e atribui à criança certas patologias, pelo simples fato 
de ela não acompanhar o ritmo da turma, e questões como a inadequação metodológica e curricular nem sempre são ponderadas nesses casos.

As dificuldades de aprendizagem em matemática podem implicar inúmeras variáveis, como: as que envolvem a formação inicial dos professores que atuarão nos anos iniciais (CURI, 2005; GATTI, 2010; NACARATO, 2010; SANTOS, KALHIL, GHEDIN, 2015); a falta de domínio dos conteúdos matemáticos (DARSIE, 1998; PALMA, 2012; NACARATO, 2010;); a descontextualização do ensino da matemática nos anos iniciais (CURI, 2005; NACARATO, 2010); as dificuldades em relação ao desenvolvimento cognitivo, e à própria complexidade da matemática; o alto nível de abstração e generalização; a hierarquização dos conceitos matemáticos (SANCHEZ, 1998, 2004), entre outras.

É necessário, portanto, considerarmos que as dificuldades de aprendizagem podem estar relacionadas a múltiplos fatores, que dizem respeito ao ensino, ao currículo escolar, ao envolvimento emocional e cognitivo, ao contexto social no qual o aluno está inserido. Dependendo das particularidades, podemos até mesmo contar com o auxílio de determinado(s) especialista(s). Porém, cabe à escola, quando não se tratar de algo clínico, buscar meios para que a situação de dificuldade seja superada, pois tanto a escola, quanto os professores precisam responsabilizar-se pelas dificuldades dos alunos e refletir sobre os fatores que vêm dificultando sua aprendizagem.

Nessa perspectiva, o ensino da matemática não pode ficar restrito à transmissão de conhecimentos matemáticos, conforme o modelo de ensino tradicional. Ao contrário, o processo pedagógico deve se dar numa dimensão crítica, que possibilite aos alunos reconhecer os modelos matemáticos presentes nos fenômenos sociais, devendo auxiliá-los a apropriar-se de ferramentas que os ajudem a desocultar, analisar, compreender, criticar e até reformular esses modelos (LIMA, 2011).

É preciso considerar que a aprendizagem exige ações intencionais e sistematizadas e deve ter "significado e sentido para quem ensina. Em contrapartida, a atividade de aprender precisa ser intencional, sistematizada, ter sentido e significado para quem aprende" (MELLO; CAMPOS, 2014, p.7). Cabe, portanto, ao professor, averiguar aquelas aprendizagens que estão em processo e realizar a "mediação necessária para que esse conjunto de conhecimentos seja apropriado pelos alunos" (MELLO; CAMPOS, 2014, p. 13).

Esse processo exige que o professor tenha conhecimentos profissionais (SHULMAN, 2005) necessários para diagnosticar o problema, propor atividades adequadas, acompanhar e avaliar a aprendizagem dos alunos. Sendo assim, é fundamental que a proposta formativa do curso de Pedagogia esteja alicerçada em um cabedal teórico-prático capaz de subsidiar o futuro 
professor no enfrentamento das diversas situações que envolvem o ensino e a aprendizagem dos alunos.

Desse modo, desde o ingresso no curso, é importante que se integre os conteúdos das disciplinas as situações da prática que permitam aos licenciando investigar os problemas, pensar em soluções e implementar ações visando soluções. Almeida e Lima (2012) e Nacarato et al. (2004), destacam a importância dos cursos de Pedagogia promoverem estudos e reflexões mais amplas sobre os conceitos matemáticos que envolvam a teoria da educação e as dificuldades voltadas para a matemática, pois estes pontos, segundo as autoras, estão relacionados com o baixo desempenho do aluno na escola, dentre tantos outros que envolvem a temática.

Levando-se em consideração os aspectos abordados, cabe-nos destacar a importância de a formação inicial ser mais debatida e problematizada, considerando a incumbência de formar profissionais para lidar com a complexidade que é a sala de aula, tendo ainda como desafio, (re)significar os conhecimentos matemáticos acumulados culturalmente, atribuindo-lhes sentidos e significados durante o processo de torna-se professor. Nesse sentido, apresentamos a seguir, a metodologia utilizada para o desenvolvimento da pesquisa.

\section{METODOLOGIA}

Na tentativa de compreender como os cursos de Pedagogia abordam as dificuldades de aprendizagem em matemática, buscamos na pesquisa qualitativa os subsídios necessários para responder à problemática do estudo. (BOGDAN, R.; BIKLEN, S., 2010).

A pesquisa teve como lócus de investigação as Instituições de Ensino Superior que ofertam o curso de Licenciatura em Pedagogia, na cidade de Porto Velho-RO, e, após o convite, obtivemos o aceite de duas instituições privadas e uma pública. Para que o sigilo de privacidade fosse mantido, substituímos seus nomes originais por nomes de rios pertencentes ao estado de Rondônia. Assim, foram denominadas: IES Rio Guaporé, IES Rio Urupá e IES Rio Jamari.

Colaboraram com a pesquisa 42 pessoas, sendo 3 professores que atuam com a formação matemática nos cursos de Pedagogia e 39 acadêmicos do $7 .^{\circ}$ período dos cursos investigados.

Dos três professores que trabalham com a formação matemática nos cursos de Pedagogia, duas professoras são formadas em Pedagogia e um professor é formado em licenciatura em Matemática, todos atuantes nos cursos de Pedagogia, e com pós-graduação. $\mathrm{O}$ tempo de atuação de cada um dos docentes nos cursos varia, porém, a maioria possui entre quatro e cinco anos, com exceção de uma professora que atua há um mês em uma das IES participantes. 
Com relação aos acadêmicos, adotamos como critério para participação no estudo os seguintes aspectos: a) por adesão; e b) estar no último ano do curso de licenciatura em Pedagogia. Respeitados os critérios, dos 59 estudantes matriculados, 39 aceitaram participar da pesquisa, todos cursando o $7 .^{\circ}$ período dos cursos de licenciatura em Pedagogia. Destes, 03 eram do sexo masculino e 36 do feminino.

Dos estudantes que aderiram ao estudo, com idade entre 20 a 54 anos, dois já possuíam nível superior, e apenas dois tinham experiência como professor.

Para o desenvolvimento da pesquisa, optamos por produzir os dados a partir de entrevistas semiestruturadas, para conhecer os professores que trabalham com a formação matemática nas IES e suas práticas; e do Grupo focal realizado com os licenciandos do curso de Pedagogia.

As entrevistas semiestruturadas (BOGDAN, R.; BIKLEN, S., 2010), realizadas com os professores que trabalham com a formação matemática, possibilitaram-nos traçar o perfil profissional e levantar o tempo de atuação nas disciplinas de formação matemática, verificar as disciplinas que lecionam e abordam a matemática, bem como os objetivos, os conteúdos e os encaminhamentos dados às disciplinas. Também verificamos, com os professores, quais conhecimentos o licenciando deve apresentar para ensinar matemática, os desafios que os futuros professores enfrentarão para esse ensino, as razões a que eles atribuem o baixo desempenho dos alunos nos anos iniciais na aprendizagem da matemática e as possibilidades para superá-los. Para facilitar a leitura dos dados, identificamos as entrevistas com os professores formadores com a sigla $E-P F$.

Com os licenciandos optamos por desenvolver Grupos Focais, apoiados principalmente nas orientações de Barbour (2009), Debus (2004), Gatti (2005) e Morgan (1988). Debus (2004) concebe grupos focais como um meio de investigação que se utiliza da dinâmica de grupo para extrair de seus participantes a forma como compreendem determinada situação, tema ou circunstância de maneira mais profunda. Para Gatti (2005, p. 12), o grupo focal é "uma técnica de levantamento de dados muito rica para capturar formas de linguagem, expressões e tipos de comentários de determinado segmento". Portanto, ao utilizá-lo como técnica, "há interesse não somente no que as pessoas pensam e expressam, mas também em como elas pensam e por que pensam". (GATTI, 2005, p. 9). Estes, foram aspectos relevantes, que nos auxiliaram na leitura dos dados e em uma análise mais precisa, permitindo-nos olhar para os detalhes que envolvem as discussões.

Para o desenvolvimento dos grupos focais, alguns aspectos foram considerados: 
Convite - Foram convidados a participar do estudo os acadêmicos que cursavam o último ano do curso de Pedagogia. Como a entrada é anual, participaram os acadêmicos do $7 .^{\circ}$ período do curso.

Quantidade de participantes - Cada sessão, contou com a participação de, no mínimo, 6, e no máximo, 12 participantes.

Local para realização - Considerando as orientações de Gatti (2005), que afirma que o local escolhido deve favorecer a interação entre os participantes, e de Barbour (2009), que faz um alerta sobre a importância de realizar os grupos focais em um ambiente que maximize a participação dos envolvidos, acordamos que as sessões seriam agendadas nas próprias instituições de ensino.

Registro, identificação e apoio - Para o registro, utilizamos gravações em áudio, com transcrição integral, e os licenciandos de Pedagogia, foram identificados numericamente de 01 a 39. Para apoiar a moderadora (pesquisadora), contamos com um relator/assistente ${ }^{3}$ no desenvolvimento dos grupos focais (BARBOUR, 2009; GATTI, 2005).

Desenvolvimento - Os Grupos Focais foram realizados em dois períodos: no primeiro momento, utilizamos as manchetes de reportagens sobre os índices de proficiência em matemática, e uma situação-problema para buscar conhecer o que os acadêmicos vivenciam e/ou vivenciaram durante a formação matemática; no segundo momento, exploramos as experiências estabelecidas durante os estágios supervisionados.

Para facilitar a leitura dos dados, empregamos a sigla $G F-E$, quando tratamos do Grupo Focal desenvolvido com os estudantes de Pedagogia.

\section{ANÁLISES E RESULTADOS}

\section{As vivências de alunos de Pedagogia e professores formadores com relação à temática dificuldades de aprendizagem em matemática}

A seguir, apresentaremos a análise interpretativa dos dados acerca do que dizem os professores formadores e os estudantes de Pedagogia sobre as experiências com a aprendizagem da matemática e com as dificuldades de aprendizagem da matemática. Tais dados foram organizados em dois eixos: o primeiro, o que dizem os professores formadores sobre a temática “dificuldades de aprendizagem" na disciplina que ministram no curso de Pedagogia; e o

\footnotetext{
${ }^{3}$ A relatora em questão é uma professora do Instituto Federal de Rondônia que se dispôs a auxiliar nas sessões do Grupo Focal.
} 
segundo, as dificuldades de aprendizagem em matemática: experiências vivenciadas pelos licenciandos de Pedagogia nos cursos.

\subsection{O que dizem os professores formadores sobre a temática "dificuldades de aprendizagem" na disciplina que ministram no curso de Pedagogia}

Os professores formadores, contaram peculiaridades das disciplinas da área da matemática que lecionam: os objetivos das disciplinas, os conteúdos abordados e a forma como são encaminhados. Apesar de não discutirem as dificuldades de aprendizagem em matemática nas disciplinas, como informaram, manifestaram suas concepções sobre os fatores que podem influenciar o sucesso e/ou fracasso da aprendizagem em matemática.

De acordo com os professores, existem alguns fatores que contribuem para o baixo desempenho dos alunos na matemática: dificuldades centradas no aluno, conforme citam os $E$ $P F$ da IES Rio Guaporé e da IES Rio Urupá, e aspectos pedagógicos, citados pelos $E-P F$ das IES Rio Urupá e da IES Rio Jamari.

Quando indagados a quem ou a que atribuem o baixo desempenho dos alunos dos anos iniciais na matemática, destacaram questões como o contexto social, o desempenho do professor, o déficit na aprendizagem dos alunos, a falta de compreensão da educação matemática, entre outros. Entretanto, os $E-P F$ atribuem basicamente ao professor a culpa pelo baixo desempenho do aluno na matemática, embora também tenham mencionado aspectos como: o contexto social, as características do conteúdo de matemática e o ensino focado na memorização e na repetição.

O fato de o aluno ser mal ou bem-sucedido em matemática na escola, segundo os $E-P F$, deve-se a múltiplos fatores, como pais que não têm formação, falta de incentivo do governo, falta de estímulo e de recursos adequados, evasão, formação do professor, falta de compromisso do professor, práticas que não atendem às necessidades dos alunos, professores que não sabem ensinar matemática, entre outros.

Quando questionados sobre as maiores dificuldades que os alunos da Educação Básica têm na matemática, os E-PF das IES Rio Guaporé e Rio Urupá responderam que elas praticamente se resumem à resolução das operações básicas, enquanto a $E-P F$ da IES Rio Jamari afirmou ser a compreensão do Sistema de Numeração Decimal (SND) que os leva às dificuldades com os algoritmos.

Os conteúdos em que os alunos mais revelam dificuldades com os algoritmos, segundo os entrevistados, são aqueles que envolvem a matemática básica e a compreensão do Sistema 
de Numeração Decimal (SND). Superá-los, no entanto, requer que o professor trabalhe “multidisciplinarmente para auxiliar os alunos a entender melhor a matemática, aplicar os conteúdos na realidade, relacionados com a vida, com o cotidiano, e o auxílio a mais da escola, que seria trabalhar com reforço" (E-PF da IES Rio Guaporé); exige "fazer um diagnóstico para apontar as dificuldades e planejar estrategicamente para ajudar" (E-PF da IES Rio Urupá); e depende de saber que, "enquanto as pessoas não pararem e perceberem que a matemática não pode ser só memorizada, ela tem que ser compreendida, aí vai melhorar" (EPF da IES Rio Jamari).

Sobre essa questão, Nacarato, Mengali e Passos (2009) destacam que a matemática vivenciada nas séries iniciais reforça, muitas vezes, a aritmética e, em especial, o ensino dos algoritmos carentes de significados, em detrimento da questão conceitual e das ideias presentes nas operações básicas, o que, somado a outros fatores, acaba contribuindo para a problemática destacada pelos professores formadores.

Acreditam os professores, que, ao finalizar o curso de Pedagogia, os licenciandos devem apresentar determinados conhecimentos para ensinar matemática, por exemplo: ser capazes de "ensinar os alunos as operações básicas, trabalhar os símbolos, contagem, numeração, e também serem capazes de entender as dificuldades que as crianças já trazem de acordo com o contexto social que elas estão inclusas" (E-PF da IES Rio Guaporé). Ter conhecimento sobre como a "criança aprende, quais as ações didáticas para inserir o conhecimento da matemática de forma que a criança possa assimilar com jogos, com materiais concretos; ter o conhecimento do nível da criança em cada fase”. (E-PF da IES Rio Urupá). Além de dominar os conteúdos, ele precisa saber “como ensinar esses conteúdos e perceber como as crianças aprendem. Porque uma das coisas que mais atrapalha o ensino de matemática é que muitos professores pensam que as crianças que estão lá na sala compreendem a matemática como eles compreendem. E não é verdade”. (E-PF da IES Rio Jamari).

Para tanto, é necessário desenvolver o conhecimento do conteúdo, o conhecimento didático e o conhecimento do currículo. Considerando que é de responsabilidade do curso de Pedagogia formar professores para ensinar matemática nos anos iniciais do Ensino Fundamental, segundo Almeida e Lima (2012, p. 455), esses cursos precisam propiciar espaços para uma formação que englobe os conhecimentos matemáticos abordados nos anos iniciais da Educação Básica, e abranja também aquilo que um dia os futuros professores deverão ensinar.

Interessante destacar que os professores formadores, mesmo diante da fragilidade de formação matemática dos estudantes, compreendem que o atual projeto dos cursos de 
Pedagogia contempla os conhecimentos teóricos e práticos que possibilitam aos licenciandos atuar com os alunos em situação de dificuldade de aprendizagem em matemática.

Apesar do posicionamento dos professores, compreendemos, pelas análises realizadas, que há muito que avançar nessa perspectiva. Os cursos, por exemplo, não problematizam as falas de pais, professores e os alunos sobre o sucesso e o fracasso escolar; não investigam como a escola lida com o problema; e, no estágio supervisionado, não problematizam essas situações.

Com efeito, muitas situações que poderiam ser investigadas, discutidas e problematizadas com relação à matemática passam despercebidas por aqueles envolvidos na formação de professores para os anos iniciais.

A seguir, com base nas vivências dos licenciandos que participaram da pesquisa, discutiremos a aprendizagem e as dificuldades de aprendizagem em matemática.

\subsection{As dificuldades de aprendizagem em matemática: experiências vivenciadas pelos licenciandos de Pedagogia nos cursos}

Nesta seção, apresentaremos a análise interpretativa dos dados referentes à vivência dos estudantes nos cursos de Pedagogia quanto à aprendizagem e às dificuldades para aprender matemática. Para a análise, utilizamos os dados produzidos a partir dos Grupos Focais, o que nos permitiu explorar o potencial da interação para promover reflexão, diálogo e debate, a partir das duas dinâmicas planejadas, sobre a forma como os estudantes de Pedagogia concebem a situação atual do ensino da matemática no Brasil; os motivos pelos quais as crianças são bem ou malsucedidas em matemática; o modo como pensam em agir como futuros professores, ao se depararem com situações de dificuldades dos alunos; o preparo que o curso fornece para lidarem com as dificuldades de aprendizagem em matemática; a contribuição dos estágios supervisionados para a formação e a maneira como são realizados na instituição.

Aqui, dispusemos o Quadro 01 para apresentar a sequência em que foram desenvolvidos os Grupos Focais. 


\begin{tabular}{|c|c|c|c|}
\hline \multicolumn{4}{|c|}{ INSTITUIÇÕES PARTICIPANTES NO GRUPO FOCAL } \\
\hline \multicolumn{2}{|c|}{ IES Rio Urupá } & IES Rio Jamari & IES Rio Guaporé \\
\hline GRUPO 1 & GRUPO 2 & GRUPO 3 & GRUPO 4 \\
\hline 11 Participantes & 06 Participantes & 12 participantes & 10 Participantes \\
\hline Sexo Feminino -11 & Sexo Feminino - 06 & $\begin{array}{c}\text { Sexo Masculino - } 02 \\
\text { Sexo Feminino - } 10\end{array}$ & $\begin{array}{l}\text { Sexo Masculino - } 01 \\
\text { Sexo Feminino - } 09\end{array}$ \\
\hline \multicolumn{4}{|c|}{ LOCAL DAS SESSÕES } \\
\hline $\begin{array}{l}\text { Sala de aula da } \\
\text { própria IES }\end{array}$ & Sala de aula da própria IES & $\begin{array}{l}\text { Sala de aula da própria } \\
\text { IES }\end{array}$ & $\begin{array}{l}\text { Sala de aula da própria } \\
\text { IES }\end{array}$ \\
\hline \multicolumn{4}{|c|}{ TEMPO DE DURAÇÃO } \\
\hline GRUPO 1 & GRUPO 2 & GRUPO 3 & GRUPO 4 \\
\hline $\begin{array}{l}\text { 1. a sessão: 1hora e } \\
40 \text { minutos }\end{array}$ & $\begin{array}{c}\text { 1. }^{\text {a }} \text { sessão: } 1 \text { hora e } 33 \\
\text { minutos }\end{array}$ & $\begin{array}{c}\text { 1. }{ }^{\text {a }} \text { sessão: } 1 \text { hora e } 36 \\
\text { minutos }\end{array}$ & $\begin{array}{c}\text { 1. a sessão: } 1 \text { hora e32 } \\
\text { minutos }\end{array}$ \\
\hline $\begin{array}{l}\text { 2. a sessão: 1hora e } \\
30 \text { minutos }\end{array}$ & $\begin{array}{l}\text { 2. }{ }^{\text {a }} \text { sessão: } 1 \text { hora e } 30 \\
\text { minutos }\end{array}$ & $\begin{array}{l}\text { 2. }{ }^{\text {a }} \text { sessão: } 1 \text { hora e } 31 \\
\text { minutos }\end{array}$ & $\begin{array}{l}\text { 2. }^{\text {a }} \text { sessão: } 1 \text { hora e } 35 \\
\text { minutos }\end{array}$ \\
\hline \multicolumn{4}{|c|}{ NÚMERO DE SESSÕ̃E REALIZADAS } \\
\hline GRUPO 1 & GRUPO 2 & GRUPO 3 & GRUPO 4 \\
\hline 02 sessões & 02 sessões & 02 sessões & 02 sessões \\
\hline
\end{tabular}

Quadro 01 - Caracterização dos Grupos Focais

Fonte: Elaboração da pesquisadora (2018).

Na primeira dinâmica, sensibilizamos os estudantes para discutir sobre a matemática escolar, a aprendizagem e as dificuldades de aprendizagem em matemática. Para isso, apresentamos algumas manchetes de veículos de comunicação que retratavam os índices de proficiência em matemática no País. E concluímos com a seguinte indagação: O que vocês têm a dizer sobre essas manchetes?

Brasil tem desempenho ruim no Pisa, inclusive na rede particular. Estudo da OCDE analisou desempenho em ciências, matemática e leitura.

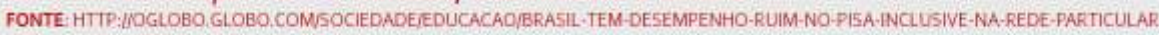

20602द, POR. POR SERGIO MATSUURA EM O7/22/2016 4:30

Pisa: Brasil tem primeira queda em matemática desde 2003 em programa de avaliaçăo.

Fonte: Jornal do Brasil- http://www.jb.com.br/pais/noticias/2016/12/06/pisa-brasil-tem-primeira-queda-em-

matematica-desde-2003-em-programa-de-avaliacao/06/12/2016 às 10 ho4 - Atualizada em 06/12/2016 às 10 ho6

Soma de fatores leva ao baixo desempenho de alunos do ensino fundamental.

As notas dos estudantes do ensino fundamental na Prova Brasil acende o alerta da educaçāo pública. Seguindo a tendência nacional, os estudantes não atingiram as médias previstas para matemática e língua portuguesa. Para educador, vários fatores favorecem o baixo desempenho.

Autor: Natália Arend fonte: Diánio da Manhá

http://www. diariodamanha. com/hoticias/ver/7257/5oma+de+fatores+leva+ao+baixo+desempenho+de+alunos+do+ensino+fundamental $28 / 02 / 2015$

Só $7,3 \%$ dos alunos atingem aprendizado adequado em matemática Fonte: Educacdo UOL -https://educacao vol. com.br/hoticias/2017/01/28/50-73-dos-alunos-atingem-aprendizado-adequado-em. matematica.htm. Mariana Tokarnia. Em 18/01/201708h26

Figura 1 - Segundo slide contendo as manchetes de reportagens Fonte: Elaboração da pesquisadora (2017).

A partir do que expuseram os $G F-E$ sobre os índices de proficiência em matemática apresentados nas manchetes e, ainda, sobre a forma como compreendem a atual situação do 
ensino da matemática no Brasil, podemos inferir que: as principais recorrências advindas das discussões estabelecidas pelos Grupos Focais evidenciam que múltiplos são os fatores responsáveis pelo baixo desempenho do País em matemática. No entanto, houve destaque em aspectos relacionados à figura do professor, e, em um único grupo, houve recorrência também dos problemas que são gerados pelo sistema e pelas políticas educacionais.

No que se refere ao professor, foram destacados aspectos que envolvem a sua dedicação, o ensino, as metodologias utilizadas por ele em sala de aula e a formação inicial, também assinalada como possível motivadora para os baixos índices da matemática no País.

No que concerne ao sistema e às políticas educacionais instituídas, mencionados durante as discussões nos GF-E, cabe destacar, que em muitas situações os pareceres, diretrizes, resoluções, entre outros, só tem burocratizado o ensino e o seu processo. Perde-se, portanto, o foco do que é realmente essencial na educação, a aprendizagem. Sem falar que, de acordo com Souza (2009), a matemática ensinada, muitas vezes, não leva em consideração os alunos, tidos como iguais em sala de aula; os conteúdos matemáticos são trabalhados sem significados, fazendo com que os alunos se sintam incapazes para aprender matemática. São, enfim, aspectos que, somados a outros, podem contribuir para os índices apresentados nas manchetes.

Ao questionarmos sobre o que pode levar um aluno a apresentar dificuldades de aprendizagem em matemática, constatamos a recorrência de aspectos relacionados a atitudes/práticas de professores e alunos que, segundo os estudantes de Pedagogia, podem levar o aluno a ter dificuldades de aprendizagem em matemática. Outro aspecto citado pelos grupos 3 e 4 foram os distúrbios como algo que pode levar um aluno a ter dificuldade de aprendizagem em matemática (DAM).

Questionamos ainda sobre o que pode levar o aluno a ser mal ou bem-sucedido em matemática. Houve recorrência nos grupos quanto à atribuição da responsabilidade à figura do professor, no caso de o aluno ser malsucedido em matemática. Quanto ao fato de ser bemsucedido, os grupos 1 e 2 trouxeram como recorrência em suas respostas que depende do aluno, enquanto para os grupos 3 e 4 foi recorrente que o sucesso do aluno depende das ações do professor.

Desse modo, retomamos Weiss (1994), que nos diz que as dificuldades de aprendizagem podem estar relacionadas com fatores externos (que envolvem a escola) ou internos (que envolvem o aluno), corroborando o que acreditamos, pois, ser mal ou bem-sucedido em matemática implica, necessariamente, na relação entre esses fatores (internos e externos), pois não há um único fator que, sozinho, garanta que o aluno seja mal ou bem-sucedido em matemática. 
Quando questionados sobre como lidariam com as situações de dificuldade em matemática, caso fossem o(a) professor(a), temos o que segue: o Grupo 1 destacou a necessidade de conhecer o histórico da criança. O Grupo 2 trouxe a avaliação diagnóstica com recorrência. Enfatizaram que é necessário fazer uma avaliação diagnóstica, e, se for o caso, mudar a estratégia ou, ainda, realizar trabalhos em grupo. No Grupo 3 não houve consenso. Além do diagnóstico, destacaram a necessidade de mudar a estratégia e trabalhar o conceito com o material concreto. O Grupo 4 afirmou que é importante o professor fazer uma autoavaliação, além de trabalhar com os jogos e o material dourado.

Acerca do como lidariam com uma situação de dificuldade na matemática, caso fossem o(a) professor(a), percebemos, nas respostas ao questionamento, que os acadêmicos compreendem que realizar uma avaliação diagnóstica para verificar o que sabem os alunos, quais estratégias utilizam, que tipo de erros cometem na resolução das atividades; auxiliaria a rever as práticas pedagógicas e a promover atividades visando amenizar ou superar as dificuldades de aprendizagem. Trata-se de aspecto já assinalado por pesquisadores como Darsie (1998), Nacarato (2010) e Weiss (1994), ao destacarem a importância da avaliação diagnóstica para detectar limites e prever possibilidades.

Portanto, o curso de Pedagogia precisaria garantir aos licenciandos, na formação inicial, os conhecimentos necessários para realizar esse diagnóstico pedagógico e prever ações capazes de superar as dificuldades (momentâneas) dos alunos.

Ao questionarmos se o curso fornece o preparo necessário para lidar com situações que envolvem as dificuldades de aprendizagem em matemática na escola em alguma disciplina, atividades extraclasse ou outras situações, afirmaram, de forma recorrente, que isso não ocorreu e, por essa razão, não se sentem preparados para lidar com tais situações no espaço escolar.

Analisadas as falas dos licenciandos de Pedagogia e dos professores formadores, referentes ao aprender e ensinar matemática para atuação nos anos iniciais do Ensino Fundamental podemos inferir que os acadêmicos de Pedagogia não estão tendo a oportunidade de uma formação matemática que lhes garantam plenas condições de lidar com as situações dilemáticas para além das teorias, e tampouco têm condições de lidar com as situações de dificuldades de aprendizagem em matemática no contexto da sala de aula. Tal situação corrobora estudos já desenvolvidos por Fiorentini et al. (2002), e Taques Filho (2012).

A seguir, discorremos sobre a vivência dos estudantes nos estágios supervisionados. 


\subsubsection{Estágio Supervisionado: o que revelam os licenciandos de Pedagogia}

Quando indagados sobre as experiências com matemática nos estágios supervisionados, integrantes do mesmo Grupo Focal, na maioria das vezes, relataram vivências bem diferentes. Para alguns alunos, o estágio foi importante porque mobilizaram conhecimentos e tentaram propor atividades que consideraram significativas para os alunos; já para a maioria dos acadêmicos, o estágio supervisionado não foi um momento importante de aprendizagem para a docência. Um dos participantes citou que não desenvolveu atividades de matemática, porque não foi uma área contemplada no estágio supervisionado.

Dificuldades de aprendizagem dos alunos com a matemática foram apontadas, pelos participantes do grupo 1 na interpretação, no raciocínio, e nas atividades de multiplicação, e o grupo 2 mencionou problemas na compreensão do que o problema solicitava; no momento de 'armar' as operações aritméticas e resolvê-las; na memorização da tabuada, sem entender o resultado. O grupo 3 destacou problemas com as quatro operações; e o grupo 4 mencionou a dificuldade em operar os cálculos. Portanto, não houve consenso nem mesmo entre os componentes dos próprios grupos, o que pode ser reflexo da forma como o estágio foi pensado, organizado e desenvolvido nas IES participantes.

A percepção dos acadêmicos do grupo 1 sobre a aprendizagem da matemática pelos alunos, durante o estágio supervisionado, foi de que apresentavam maior dificuldade na interpretação de problemas, por falta de leitura e raciocínio, e nas quatro operações básicas. Segundo o grupo 2, a interpretação do que se pedia, o raciocínio lógico, a multiplicação, os cálculos e a resolução de problemas oferecem os maiores entraves. O grupo 3 mencionou que as quatro operações, as medidas, o entendimento dos conceitos utilizados nos livros e a resolução de problemas causaram dificuldades. E, para o grupo 4, os maiores embaraços surgiram com as quatro operações.

Para finalizar, indagamos se alguma ação foi feita com os alunos que revelaram dificuldades de aprendizagem em matemática durante os estágios supervisionados, ao que, os estudantes pertencentes aos grupos 1 e 2 responderam de imediato que nada foi feito, enquanto os estudantes dos grupos 3 e 4 ficaram divididos ao dar suas respostas, sem explicitar as ações.

A vivência relatada pelos alunos incomoda-nos profundamente. As crianças, quando não acompanham as atividades propostas pelos professores, ficam, geralmente à margem do processo. Parece existir uma ideia, ainda que não explicitada conscientemente, de que é "natural" que algumas crianças não aprendam e não sejam bem-sucedidas. Essa naturalização cria um contingente de crianças invisíveis na sala de aula, agravando situações que poderiam 
ser resolvidas com diagnóstico e acompanhamento adequado em sala de aula e, por vezes, para além dela.

A maioria dos estudantes vivenciou durante os estágios alguma dificuldade de aprendizagem dos alunos com a matemática, principalmente nas quatro operações, de forma recorrente nos Grupos Focais desenvolvidos, embora outros aspectos, como a resolução de problemas e a interpretação, também tenham sido mencionados em menor proporção.

Vimos, a partir do que afirmaram os acadêmicos, que somente dois estudantes - um pertencente ao grupo 3 e o outro participante do grupo 4 - relataram ter realizado ações diferenciadas com os alunos que apresentaram dificuldades com a matemática. Os estágios, portanto, não se constituíram em práticas que possibilitassem aos acadêmicos a práxis necessária para lidar com as dificuldades de aprendizagem em matemática na escola.

Ao analisarmos as vivências e os pensamentos dos acadêmicos de Pedagogia nos Grupos Focais desenvolvidos, percebemos um certo distanciamento entre a formação matemática ofertada nos cursos (universidade) e aquela vivenciada durante os estágios pelos estudantes (escola), pois, em vários momentos, os acadêmicos mostraram-se inseguros diante das situações que os aguardam após formados. Isso nos faz concordar com Souza (2009), ao defender a necessidade de maior aproximação entre escola e universidade, pois, segundo ele, é uma aproximação necessária para conhecer os alunos, a forma como entendem o conhecimento matemático que lhes é ensinado e, ainda, suas necessidades, pois somente assim, os futuros professores conseguirão perceber as diferenças existentes entre os aprendentes.

Diante do exposto, as entrevistas com os professores, bem como o Grupo Focal com os acadêmicos de Pedagogia, permitiram constatar que o estágio obrigatório possui diferentes formas de oferta e acompanhamento nas IES pesquisadas. Há, conforme relato dos professores formadores e acadêmicos, um profissional responsável pelo estágio, geralmente, um professor ou coordenador de estágio, porém, as orientações e, quando necessário, os acompanhamentos, são feitos somente na instituição formadora. Portanto, durante os estágios supervisionados na escola, não há acompanhamento de um professor ou, do professor que atua com a formação matemática, o que, de algum modo, auxiliaria e enriqueceria a formação docente, tendo em vista que é nos estágios supervisionados que as limitações, as inseguranças, bem como as aprendizagens e a possibilidade de criar e empreender novas metodologias podem se manifestar. 


\section{CONSIDERAÇÕES}

Ao analisarmos as vivências de alunos de Pedagogia e professores formadores com relação à temática dificuldades de aprendizagem em matemática, buscamos conhecer o que ensinam da matemática, saber se discutem as dificuldades para aprender matemática e vislumbrar os fatores que podem influenciar no sucesso ou no fracasso da aprendizagem em matemática. No tocante a essas questões, em razão da própria carga horária reduzida, os conteúdos são abordados de forma genérica e sem uma aproximação adequada com a escola.

Acreditamos, após a imersão, que o estudo possibilitou, que as dificuldades de aprendizagem em matemática precisam ser não somente assumidas como política de formação, pelos cursos de formação inicial, mas também continuamente problematizadas nas escolas, nos cursos de formação continuada, pelos acadêmicos na formação inicial e compreendidas como necessárias nas diretrizes que norteiam a formação do pedagogo. Caso contrário, não há como reverter a atual situação do País, no que diz respeito à matemática.

Concebemos, outrossim, que a matemática precisa ser (re)significada e acreditamos que os espaços promissores e favoráveis a essa (re)significação sejam, além dos espaços escolares, e de formação continuada, os cursos de formação inicial de professores, justamente, por oferecer formação profissional e momentos de reflexão.

Reconhecemos, no entanto, que alguns avanços já ocorreram ao longo dos anos. Contudo, não foram suficientes para minimizar os entraves da realidade na qual estamos submersos. Em nossa concepção, a discussão sobre o fracasso escolar, e, nesse contexto, o problema de crianças em situação de dificuldades de aprendizagem, deve estar articulada às políticas públicas de ensino e às demais instituições, para que possam, de alguma maneira, dar suporte aos processos de investigação e intervenção, quando se fizerem necessários.

\section{AGRADECIMENTOS}

Agradecemos aos gestores, professores, acadêmicos e coordenadores de curso, que cederam o seu tempo e se dispuseram a colaborar no desenvolvimento da pesquisa. Ao Instituto Federal de Rondônia - IFRO, a Universidade Federal do Mato Grosso - UFMT e a Fundação de Amparo à Pesquisa de Rondônia - FAPERO pelo apoio. 


\section{REFERÊNCIAS}

ALMEIDA, Marlisa Bernardi de; LIMA, Maria das Graças de. Formação inicial de professores e o curso de Pedagogia: reflexões sobre a formação matemática. Ciência \& Educação, Bauru, SP, v. 18, n. 2, 2012. https://doi.org/10.1590/S1516-73132012000200014

BARBOUR, Rosaline. Grupos Focais. Porto Alegre: Artmed, 2009. (Coleção Pesquisa Qualitativa).

BOGDAN, Robert; BIKLEN, Sari. Investigação qualitativa em educação: uma introdução à teoria e aos métodos. Porto: Porto Editora, 2010.

CIASCA, Silvya Maria. Distúrbios de aprendizagem: Proposta de avaliação interdisciplinar. São Paulo: Casa do Psicólogo, 2003.

COUTO, Brígida. O professor articulador e o atendimento dos alunos em situação de dificuldade de aprendizagem matemática em escolas Estaduais de Cuiabá- MT. Dissertação (Mestrado) - UFMT, Cuiabá, 2016.

CURI, Edda. A formação matemática de professores dos anos iniciais do ensino fundamental face às novas demandas brasileiras. Revista Iberoamericana de Educación, Madri, v. 37, n. 5, p. 1-10, 2005. Disponível em: 〈http://www. rieoei. org/deloslectores/1117Curi.pdf〉. Acesso em: 10 de set. 2016.

DARSIE, Marta M. P. A reflexão distanciada na construção dos conhecimentos profissionais do professor em curso de formação inicial. Tese (Doutorado) - FEUSP, São Paulo, 1998.

DEBUS, M. Manual de excelência em la investigación mediante grupos focales. Washington: Porter Novelli, 2004.

FIORENTINI, Dário. et al. Formação de professores que ensinam Matemática: um balanço de 25 anos de pesquisa brasileira. Educação em Revista - Dossiê Educação Matemática UFMG, Belo Horizonte, n.36, 2002.

FONSECA, Lilian Leandro Da. Diagnóstico e encaminhamento dados por professores a alunos em situação de dificuldade de aprendizagem em matemática. Cuiabá, MT: Dissertação (Mestrado) - UFMT, Cuiabá-MT, 2014.

GATTI, Bernadete Angelina. Grupo focal na pesquisa em ciências sociais e humanas. Brasília: Líber Livro, 2005.

GATTI, Bernadete A. Formação de Professores no Brasil: características e problemas. Educação e Sociedade, Campinas, v. 31, n. 113, p. 1.355-1.379, 2010. Disponível em: < http://www.scielo.br/pdf/es/v31n113/16.pdf>. Acesso em: 28 set. 2016.

GATTI, Bernadete A.; NUNES; Mariana M. R. (Orgs.). Formação de professores para o ensino fundamental: estudo de currículos das licenciaturas em pedagogia, língua português, matemática e ciências biológicas. São Paulo: FCC/DPE, 2009. (Coleção Textos FCC, n. 29). 
LIMA. Maria Almeida de. Diagnóstico, compreensão e interpretação das dificuldades de aprendizagem em matemática: o processo desenvolvido por uma acadêmica, bolsista do OBEDUC-UFMT. DARSIE, Marta Pontin; PAULA, Jaqueline Borges (orgs.). Pesquisas em educação Matemática e Ciências: Projeto Observatório da Educação na Universidade Federal do Mato Grosso, 2017, p. 105 a 117.

LIMA, Simone Marques. A formação do pedagogo e o ensino da matemática nos anos iniciais do ensino fundamental. Dissertação (Mestrado) - UFMT, Cuiabá, 2011.

MELLO, Maria A; CAMPOS, Douglas A. de. A teoria histórico-cultural e a problemática dos processos de ensino e aprendizagem. Caderno da Pedagogia. São Carlos, ano 7, v.7, n.14, p.6-18, jan./jun., 2014.

MELLO, Maria A. Aprendizagens sem dificuldades: a perspectiva histórico-cultural. APRENDER - Caderno de Filosofia e Psicologia da Educação, Vitória da Conquista, ano v.2, n. 9, p. 203-218, 2007.

MORGAN, D. L. Focus Group as Qualitative Research. Newbury Park, Sage Publication, (Qualitative Research Methods Series 16), 1988.

MULLER, Gessilda Cavalheiro. Dificuldades de aprendizagem na matemática: um estudo de intervenção pedagógica com alunos do $4^{\circ}$ ano do ensino fundamental. Tese (Doutorado). UFRS, Porto Alegre, 2012.

NACARATO, Adair M. A Formação Matemática das Professoras das Séries Iniciais: a escrita de si como prática de formação. Bolema, Rio Claro, v. 23, n. 37, p. 905-930, 2010.

Disponível em: www.periodicos.rc.biblioteca.unesp.br/index.php/bolema/article/view/4298

NACARATO, A.M.; MENGALI, B. L. S.; PASSOS, C.L.B. A matemática dos anos iniciais do ensino fundamental - tecendo fios do ensinar e do aprender. Belo Horizonte: Autêntica Editora, 2009.

NACARATO, Adair Mendes; PASSOS, Cármen Lúcia B.; CARVALHO, Dione Lucchesi. Os graduandos em pedagogia e suas filosofias pessoais frente à matemática e seu ensino. Zetetiké, nº 21, vol. 12, p. 9-33, janeiro/junho de 2004.

PALMA, Rute Cristina Domingos da; MOURA, Anna Regina Lanner de. Formação inicial de professores e a produção de sentidos sobre o aprender e ensinar matemática. Revista de Educação Pública, Cuiabá, MT, v.21, n.47. p.639-659, set./dez., 2012. Disponível em: www.periodicoscientificos.ufmt.br/ojs/index.php/educacaopublica/article/view/863/662

PLAZZA, Eliane.M. Avaliação diagnóstica: Saberes e dificuldades em Matemática revelados por alunos do $4^{\circ}$ ano do ciclo I do Ensino Fundamental. In: CURI, Edda. Professores que ensinam matemática. Conhecimentos, crenças e práticas. São Paulo: Terracota, 2010.

RÊGO, Francisco R. do. As dificuldades dos alunos da em Virgílio Correia Lima em operações básicas com números naturais, inteiros e racionais. Dissertação (Mestrado). Juazeiro do Norte, CE, 2014. 
SANCHEZ, Jesús Nicasio Garcia. Dificuldades de Aprendizagem e Intervenção Psicopedagógica. Porto Alegre: Artmed, 2004.

SÁNCHEZ, Jesús N. G. Historia y concepto de lãs dificultades de aprendizaje. In: Dificultades de aprendizaje. Madrid (ES): Ed. Sintesis S.A., 1998.

SANTOS, Edlauva O. dos; KALHIL, Josefina B.; GHEDIN, Evandro. A formação matemática no curso de Pedagogia: o que revelam as matrizes curriculares. Revista REAMEC - Revista do Programa de Doutorado da Rede Amazônica de Educação em Ciências e Matemática, Cuiabá-MT, n.03, p., dez. 2015, Disponível em: http://revistareamec.wix.com/revistareamec. Acesso em: 23 mar. 2018.

SHULMAN, L. S. Conocimiento y enseñanza: fundamentos de la nueva reforma. Profesorado. Revista de Currículum y formación del profesorado, 9, 2, p. 1-30, 2005. Disponível em: < http://www.ugr.es/ recfpro/Rev92.html>. Acesso em: 12 de jul. de 2018.

SILVA, Ana C. P. da; LUZIO, Cristina A.; SANTOS, Kwame Y. P. dos. A explosão do consumo de ritalina. Revista de Psicologia da UNESP, Assis, SP, v.11, n.2, 2012.

SILVA, Marta A. E.; DARSIE, Marta M. P. Situação de dificuldade de aprendizagem em matemática: concepções e intervenções de professores articuladores que atuam no ensino fundamental. Revista Eletrônica Documento/Monumento, v.13, p. 162-167, 2014.

SILVA, Silvia H. F. Professoras do $3^{\circ}$ ano do ensino fundamental frente as dificuldades de aprendizagem em matemática e as decisões de encaminhamento para apoio psicológico e/ou reforço escolar. Dissertação (Mestrado)- PUC, Campinas, 2014.

SISTO, F., BORUCHOVITCH, E., Fini, L. D. T., BRENELLI, R. P., \& MARTINELLI, S. C. Dificuldade de aprendizagem no contexto psicopedagógico. 3. ed. Petrópolis, RJ: Vozes, 2004.

SOUZA, J. F. de. Construindo uma aprendizagem significativa com história e contextualização da matemática. Dissertação (mestrado) - UFRRJ, Rio de Janeiro, 2009.

SULEIMAN, Amal R. Concepções dos professores em relação à matemática, a seu ensino e às dificuldades dos alunos. Revista Acta Scientiae, Canoas, RS, v.18, n.2, maio/ago. 2016.

TAQUES FILHO, Lincoln S. Características da formação matemática das futuras professoras das séries iniciais do ensino fundamental a partir de cursos pedagogia de Curitiba. Revista Intersaberes, vol. 7 n.14, ago./ dez, 2012, p. 262- 277. Disponível em: https://www.uninter.com/intersaberes/index.php/revista/article/viewFile/323/196

VIANA, Gabrielle S. Contribuição das deleções para o fenótipo Dificuldade de Aprendizagem da Matemática. Dissertação (Mestrado) - UFMG, Minas Gerais, 2011.

WEISS, Maria L. L. Psicopedagogia clínica: uma visão diagnóstica, 2. ed. Porto Alegre: Artes Médicas, 1994. 
Submetido em: 10 de junho de 2020.

Aprovado em: 19 de junho de 2020. 